\title{
The International Legal Concerns on Climate Change Regime: Taiwan's Perspective
}

\author{
Yiyuan $\mathrm{Su}{ }^{*}$
}

Climate change is an emerging environmental issue. To prevent possible trade sanctions from the industrialized trading partners, Taiwan proposed several policies to mitigate greenhouse gas emissions. This includes their preparation of the Greenhouse Gas Reduction Act is under legislature review and the Statute for Renewable Energy Management. Because Taiwan is not a member of the United Nations, it is excluded from participation in the United Nation Convention on Climate Change and lacks access to the flexible mechanisms defined under the Kyoto Protocol. The Taiwan Environment Protection Administration plans to encourage the local emitters to acquire foreign reduction credits to offset domestic emissions. This article approaches Taiwan's mitigation policies and measures from an international legal perspective. It also introduces adaptation policies and recommends that the government establish a special national adaptation team to prepare data and criteria for risk prioritization. Finally, this paper recommends that the Parties of the UNFCCC adopt the 'universal apply' principle for climate change and allow any governmental agency whose governing matters are covered by the convention, to participate and share emission-reduction responsibilities.

\section{Keywords}

Climate Change, Taiwan, EPA, Mitigation, Adaptation, UNFCCC, Flexible Mechanisms

* Assistant Professor of International Law at National Chung Hsing University, Taiwan. LL.B. (Soochow), M.B.A. (Tamkang), LL.M./S.J.D. (American Univ.). The National Science Council ("NSC") of the Executive Yuan of the Republic of China supports this article (project number: NSC100-3113-P-007-001). The author may be contacted at: su.yiyuan@gmail.com or suyiyuan@nchu.edu.tw / Address: 250 Kuo-Kuang Rd., Taichung 402, Taiwan R.O.C. 


\section{Introduction}

Climate change is one of the biggest environmental concerns in the 21 st century. The global greenhouse effect caused by anthropogenic greenhouse gas ("GHG") emissions into the atmosphere has led to rising global temperatures, endangering the climate system. The international community is trying to stabilize global GHG emissions through cooperation from multiple sectors, information sharing on the reduction of GHG emissions with stakeholders, and the prevention of adverse effects caused by climate change. ${ }^{1}$ As the 17th leading merchandise exporter among the World Trade Organization ("WTO") members, 2 Taiwan also produces $1 \%$ of all global greenhouse gas emissions. ${ }^{3}$ Although Taiwan is neither a member of the United Nations, nor United Nations Framework Convention on Climate Change ("UNFCCC"), it is still aligning its national policies and measures on carbon dioxide emission reduction rates with the UN guidelines. By complying with UN and UNFCCC policies and measures, and following GHG emission reduction rates according to the Kyoto protocol, Taiwan could be protected from low carbon regulations imposed by its trading partners in the European Union or the United States.

In accordance with the natural disaster hotspot project of the World Bank in 2005, Taiwan is a probable location for multiple natural disasters. 4 Climate change might furthermore intensify the strength and frequency of natural disasters increasing the damage to Taiwan. Early preparations are crucial to the reduction of adverse consequences including human loss caused by climate change. The cost of mitigating and adapting to the effects of climate change is still high, because of its unique international legal status; Taiwan is unable to request any scientific or financial assistance from international organizations and UNFCCC. 5 Taiwan is thus forced to independently use its internal efforts and funds to develop climate-related policies and measures and increase capacities. 6 This puts Taiwan in an unfair and unequal position

1 United Nations Framework Convention on Climate Change art. 2 (Mar. 21, 1994), U.N. Doc. A/AC.237/18 (Part II)/ Add.1, reprinted in 31 I.L.M 848 (1992).

2 WTO, International Trade Statistics 201013 (2010), available at http://www.wto.org/english/res_e/statis_e/ its2010_e/its2010_e.pdf (last visited on May 5, 2011).

3 Shu-Hung Shen, Taiwan's Climate Change Mitigation, The Korea Times, Nov. 26, 2009, available at http://www.koreatimes.co.kr/www/news/opinon/2011/01/198_56189.html (last visited on May 5, 2011).

World Bank, Nature Disaster Hotspots: A Global Risk ANalysis 2 (2005).

Yiyuan (William) Su, The Effects of the Kyoto Protocol on Taiwan, 6 Sustainable Dev. L. \& Pol'y 51, 51 (2006).

The Republic of China (Taiwan) has withdrawn its representation of China from United Nations since 1971. See G. A. Res. 2758, at 2, U.N. GAOR, 26 th Sess., Supp. No. 29, U.N. Doc. A/8429 (Oct. 25, 1971), available at http://daccessdds-ny.un.org/doc/RESOLUTION/GEN/NR0/327/74/IMG/NR032774.pdf?OpenElement (last visited on May 5, 
when it comes to sharing emission-reduction responsibilities in combating climate change, especially because Taiwan must expend higher costs than other developing countries to reach the target emission level.

This paper is divided into nine parts, including this introduction, which explains the current development of climate-change controls in Taiwan. The second part discusses the structure of the Taiwanese government and how it controls climate-related issues. The third and fourth parts analyze the possibilities for Taiwan to participate in the UNFCCC as an observer. The fifth part pays attention to several new policy and legislative developments in Taiwan's climate-change mitigation and adaptation activities. The sixth part addresses the specific mitigation measures taken by the Taiwan Environmental Protection Administration ("EPA") to reach its policy announcement. The seventh part introduces Taiwan's national adaptation plan and address several concerns Taiwan faces. The eighth part explains the necessity of legal capacity building to establish local legal principles for future climate-related regulations. The ninth part provides a few conclusions and an outlook for the future.

\section{The Governmental Structure in Dealing with Climate Change}

Taiwan has not developed its sustainable development strategies and priorities yet. The Executive Yuan, which is the enforcement branch of the government of the Republic of China (Taiwan), is the only agency to design such policy for Taiwan. With a goal to follow the sustainable development principles adopted by the 1992 Rio Declaration on Environment and Development, ${ }^{7}$ the Executive Yuan established the National Council for Sustainable Development ("NCSD") in 1997.8 The Minister without portfolio, appointed by the premier of the Executive Yuan, chairs the NCSD and the EPA and is currently serving secretarial works. Thus far, the NCSD has developed the following sustainable development strategies: Agenda 21 Strategic Guidelines for ROC's

2011). Taiwan currently is not member of United Nations because of its 'State' requirement of participation. However, Taiwan has official diplomatic relationship with 23 countries and they all recognize the Republic of China in Taiwan is a State.

7 The Rio Declaration on Environment and Development, June 3-14, 1992, Report of the United Nations Conference on Environment and Development, Principle 1, U.N. Doc. A/CONF.151/26 (vol. I), Sales No. E.73.II.A.14 (Aug. 12, 1992), available at http://www.un.org/documents/ga/conf151/aconf15126-1annex1.htm (last visited on May 5, 2011).

8 National Council for Sustainable Development Network, Introduction and History, available at http://sta.epa.gov.tw/ nsdn/en/introduction/introduction.htm (last visited on May 5, 2011). 
Sustainable Development ("Agenda 21 Strategic Guidelines”) in 2000; Action Plan for Sustainable Development in 2002;9 Taiwan Declaration of Sustainable Development; 10 Sustainable Development Indicator System 11 in 2003; Taiwan Agenda 21 Vision and Strategic Guidelines for National Sustainable Development ("Taiwan Agenda 21")12 in 2004; and the Taiwan Agenda 21 Vision and Strategies for National Sustainable Development 13 in 2010 . These actions or guidelines are administrative orders regulating only the lower bureaus. The contents of sustainable development are not defined by discussions with the public, but by the political party in power. The nature of such administrative characteristics makes it easy to change a strategy when the political power shifts; continual implementation is not, thus, guaranteed. Take for instance, the sustainable environment and economic development guidelines list in the Agenda 21 Strategic Guidelines of 2000 are only relevant when the Nationalist Kuomintang ("KMT") Party controlled the government. When the Democratic Progress Party ("DPP") took power in the 2000 presidential election, the new government revised the Taiwan Agenda 21 with a new structure, while also announcing a nuclear-free policy initiative as its sustainable energy and economic development goal. Furthermore, the plan in 2004 added sustainable society into its new strategic guidelines, which was based on the Agenda 21 Strategic Guidelines in 2000. After the KMT won the presidential election again in 2008 , the new government was inclined to repudiate the nuclear-free policy. It also implemented the same strategy for sustainable development, but now contained an entirely different vision for a sustainable environment, economy, and society. As it is shown, sustainable development policies can be easily overturned with the shift of the governing power.

The easily shifting sustainable development policies are neither applicable to the long-term needs of the country, nor consistent with the requirement of sustainability. 14 The inconsistent and unregulated sustainable development policies reflect the importance of the public in such discussions. With the people's consent and participation, the strategies will be more firmly implemented and monitored, and will not be easily altered with political shifts. Public participation is important in the implementation of a steady sustainable development strategy. With their help, the government will be able to pinpoint the priority issues, and establish sustainable

9 Id. Action Plan, available at http://sta.epa.gov.tw/nsdn/en/project/index.htm (last visited on May 5, 2011).

10 Id. The Taiwan Declaration on Sustainable Development, available at http://sta.epa.gov.tw/nsdn/en/development/ index.htm (last visited on May 5, 2011).

11 Id. Taiwan Sustainable Development Indicators, available at http://sta.epa.gov.tw/nsdn/en/TSDI/INDEX.htm (last visited on May 5, 2011).

12 Id.

13 Id. Taiwan Agenda 21, available at http://sta.epa.gov.tw/nsdn/en/agenda/index.htm (last visited on May 5, 2011).

14 Natalia Mirovitskaya \& William Ascher, Guide to Sustainable Development and Environmental Policy 74 (2001). 
development priorities and strategies. 15 Once the sustainable development priorities are set, an independent agency needs to be appointed to implement the sustainable development strategies. An independent agency can implement and promote Taiwan's sustainable development goals and strategies.

The NCSD is a department directly controlled by the Premier. The governing party controls the administrative power of the NCSD. The administrative branch can easily affect the promotion of the sustainable development priorities because of its varying political agendas. For example, the Basic Environmental Act ${ }^{16}$ was initiated and passed by the Legislative Yuan in 2002. Article 23 of the Act requires that the government achieve the goal of a nuclear-free homeland.17 However, in 2010, the succeeding KMT government removed the nuclear-free clauses from the Taiwan's Agenda 21. It is apparent that the two political parties had different points of view in the development of nuclear energy. The NCSD must obey orders from the Executive Yuan even though it clearly violates the nuclear-free statements under Article 23 of the Basic Environment Act. It is evident that the NCSD should be an independent agency established by law and engage in implementing Taiwan's sustainable development priorities and strategies.

\section{The Participation to the UNFCCC}

The Taiwanese government recognizes that climate change has the potential to cause severe damage on living creatures and the natural environment. Because Taiwan is not a member of the UN, it is not allowed to ratify UNFCCC or the Kyoto Protocol. Thus, the related bureaus should prepare for both mitigation and adaptation policies that will eventually be approved by the Executive Yuan. Since it is difficult to gain UN membership, on September 21, 2009, the Taiwanese government unilaterally announced that: "Taiwan is seeking the opportunity to participate in the Conference of the Parties ("COP") of the UNFCCC as an observer." 18

Article 7, paragraph 6 of the UNFCCC states that: "Any body or agency, whether national or international, governmental or non-governmental, which is qualified in

\footnotetext{
15 David Hunter, James Salzman \& Durwood Zaelke, International Environmental Law and Policy 205 (2d ed. 2002).

16 Basic Environment Act (Dec. 11, 2002) (Taiwan), the Gazette of the Office of the President, No. 6493, at 4, available at http://db.lawbank.com.tw/Eng/FLAW/FLAWDAT0201.asp (last visited on May 5, 2011).

17 Id. art. 23.

18 Taiwan Environmental Protection Administration, Towards UNFCCC, available at http://unfccc.epa.gov.tw/unfccc/ english/index.html (last visited on May 5, 2011).
} 
matters covered by the Convention, and which has informed the secretariat of its wish to be represented at a session of the Conference of the Parties as an observer, may be so admitted unless at least one third of the Parties present object." 19 Based on this paragraph, any agency that is responsible for regulating domestic GHG emissions reduction and adaptation activities or measures, can apply to participate in the COP meeting as an observer. Presently, the Taiwanese government is considering submitting an application for the EPA to observe the session of the COP.

Because the EPA is a secretariat branch that only deals with secretariat efforts in preparing for domestic mitigation regulations for the NCSD, however, the bureau's attendance will not benefit the Taiwanese government in its efforts to mitigate the effects of climate change. If the Taiwanese government is searching for an opportunity to participate in it as an observer, the Executive Yuan is the only qualified agency because its responsibilities include both mitigation and adaptation activities. The challenge is whether the Executive Yuan could receive approval from two-thirds of the Parties. 20

The observer of the COP is neither entitled to, nor enjoys the benefits or rights of the Convention. However, from the climate negotiations, the observer can gain insight toward developing domestic policies or actions. It can use this information to educate its delegates and officers and to assist in expanding the capabilities of the institutions. ${ }^{21}$ The observer application to the Secretariat shall be done annually before the COP meeting.

\section{Participation under the Climate Regime}

Taiwan releases GHG emissions to the atmosphere and should therefore share the liability of the effects of anthropogenic emissions. Based on the burden-sharing and equity principle, Taiwan should share the obligation of making a greener world. Although Taiwan is currently not subject to the Kyoto's reduction commitments, its contribution of almost $1 \%$ of the global GHG emissions should be considered a reason to share the responsibility with the global community. The appropriate measures needed for Taiwan to gain recognition as a participant under the climate-change regime is not only an international law issue, but also a challenge for the Parties of the

Supra note 1, art. 7.

20 UNFCCC, Framework Convention on Climate Change, July 8-19, 1996, Organizational Matters Adoption of the Rule of Procedure, art. 7, para. 1, U.N. Doc. FCCC/CP/1996/2 (May 22, 1996), available at http://unfccc.int/resource/ docs/cop2/02.pdf (last visited on May 5, 2011).

21 Supra note 5, at 53. 
Convention. According to Article 122 and Article 22 of the UNFCCC,23 only States and regional economic integration organizations ("REIO") are qualified to ratify the Convention. Taiwan is neither the member of a regional organization, nor that of the UN. If the Parties would like to invite Taiwan to share in the GHG emissions reduction responsibility, further explanation or modification of the existing article might be necessary.

\section{Taiwan's Climate Change Policy and Related Regulations}

\section{A. Reduction Target}

In 2008, Taiwan depended on up to $99.23 \%$ of imported energy and its GHG emission was 289.8 $\mathrm{MTCO}_{2} \mathrm{eq}$ (million tons of $\mathrm{CO}_{2}$ equivalent). 24 President Ma Ying-Jeou plans to reduce domestic GHG emissions to the same levels as 2008 by 2020, and by 2050, he wishes to reduce the emissions level by $50 \%$ to reach the same level it was in $2000.25 \mathrm{In}$ 2009, the EPA drafted the GHG Reduction Act, ${ }^{26}$ which serves as the legal basis for conducting GHG emissions reduction measures, and then submitted it to the Legislative Yuan (the legislative branch of Taiwan) for review. If this proposal passes, the domestic emissions sources will have to comply with the emissions reduction target. 27

The draft GHG Reduction Act does not include an emission reduction target, but only a clause for carbon inventory investigations. This bill provides only the legal ground for the government to develop domestic mitigation measures without adaptation measures or activities. The government might be concerned that such an

22 Supra note 20, art. 1, para. 6: "Regional economic integration organization" means an organization constituted by sovereign States of a given region which has competence in respect of matters governed by this Convention or its protocols and has been duly authorized, in accordance with its internal procedures, to sign, ratify, accept, approve or accede to the instruments concerned.

23 Supra note 1, art. 22, para. 1: The Convention shall be subject to ratification, acceptance, approval or accession by States and by regional economic integration organizations.

24 Supra note 18, Taiwan's GHG Emission \& The energy Supply Situation and Consumption, available at http://unfccc.epa.gov.tw/unfccc/english/04_our_efforts/03_efforts.html (last visited on May 5, 2011).

25 Id. Action to Reduce GHG Emission, available at http://unfccc.epa.gov.tw/unfccc/english/04_our_efforts/ 060_actions.html (last visited on May 5, 2011).

26 Environmental Protection Administration Executive Yuan (Taiwan), 溫室氣體減量法草案：97年2月4日䢪請立法院 審議版本 [The Draft of Greenhouse Gas Reduction Act 2008] (only available in Chinese), available at http://www.epa.gov.tw/ch/aioshow.aspx?busin=12379\&path=12405\&guid=5c2aad3c-ff22-4 7a 2 -b $1 \mathrm{e} 4$ 8df8b68167e0\&lang=zh-tw (last visited on May 5, 2011).

27 Id. arts. $13 \& 14$. 
emissions reduction target would highly increase the reduction cost on the emission sources, reducing the benefits and increasing the operation cost.

This proposal does not consider President Ma's GHG emission reduction plan as the national reduction target. It neither sets up a reduction target, nor defines a specific time period for reduction behavior. According to Article 6 of this Act, the EPA shall develop a national mitigation policy based on domestic economy, energy, environment, and global development conditions. ${ }^{28}$ Article 13 of the Act states that: "[T]he EPA should consider the decisions of COP, meeting of the Parties ("MOP") and related meetings on global GHG emissions reduction to decide Taiwan's total GHG emissions amount." 29

This legislation does not include national targets for GHG emission reduction. Although the government has imposed emission caps on pollution emissions, companies are not obligated to obtain the reduction target. Even dereliction is not subject to punishment. All mitigation policies and measures proposed by the EPA shall be approved by the Executive Yuan. This legislation would grant total power to the EPA and the Executive Yuan to choose a baseline year and reduction schedule. Therefore, this proposal is not "cap-and-trade system," but only mass emission amount control. It can neither reduce GHG emissions from pollution sources, nor fulfill the reduction plans proposed by President Ma. The schedule for emission trading is unpredicted and the opportunities for actual exchanging would be very limited. The reduction target proposed by President Ma became a policy announcement without binding force; it can be hardly recognized as a collaborative measure in international mitigation actions.

\section{B. Methodologies}

This proposal requires that emission sources engage in voluntary emission-investigation activities and register their emission records at the authorized agency. ${ }^{30}$ The government derived the rules from ISO 14064/14065 and created the national standard CNS 14064 as a method to inventory GHG levels on all sources of pollution. 31 The related methodologies on monitoring, verification, and validation shall also follow the CNS 14064 standard. However, Article 4, paragraph 1, subparagraph (a) of the Convention states that: "Parties shall establish and adopt those methodologies approved by the COP to engage in national inventory investigations." 32 The participants

28

29

30

1 Taiwan GHG Emission Registry, $Q$ \& A, available at http://estc10.estc.tw/ghgenglish/QA_Detail.asp?id=4 (last visited on May 5, 2011).

32 Supra note 1, art. 4, para. 1, subpara (a). 
of the flexible mechanisms shall also adopt these comparable methodologies to develop their projects. Taiwan can only participate in the voluntary reduction activities without the obligation to comply with the commitments of using comparable methodologies. Because CNS 14064 is a unique methodology in the market, however, Taiwan's exclusive methodology proposal would make it more difficult for its partners to access the Taiwan's information. If domestic pollution sources search for foreign investment for their emission-reduction project on carbon neutralization, this proposed exclusive methodologies will increase the expenses on methodologies transferring.

The exclusive methodology might also restrain the development of the third party services on monitoring, verification, and validation activities. The usage of comparable methodologies can introduce more firms and experts into the third-party service market and provide various choices for project developers and pollution sources. Therefore, it can not only create more employment opportunities, but also assist in the development of the new industry services within the market.

\section{Scope of Greenhouse Gas as Pollutants}

The greenhouse gases regulated by the Kyoto Protocol contains carbon dioxide (" $\mathrm{CO}_{2}$ "), methane (" $\mathrm{CH}_{4}$ "), nitrous oxide (" $\mathrm{N}_{2} \mathrm{O}$ "), hydrofluorocarbons ("HFCs"), perfluorocarbons ("PFCs") and sulphur hexafluoride ("SF6").33 Article 3 of the proposed GHG Reduction Act regulates the emission of these six greenhouse gases to the atmosphere. ${ }^{34}$ However, Article 21 of the Basic Environment Act only calls for measures to reduce the emission of $\mathrm{CO}_{2} .{ }^{35}$ Even though the Basic Environment Act is only a policy-development guideline, all governments are called upon to take this bill into consideration when preparing for environmental-related policies and measures. With its inclusion of five other GHG pollutants in addition to $\mathrm{CO}_{2}$, the GHG Reduction Act extends the scope of the Basic Environment Act. The legislation should be consistent, especially because the Basic Environment Act is the basis for all environment regulations. With its recognition of five additional GHGs, the GHG Reduction Act will raise much more operational cost on local emitters than before. Therefore, the government should modify the scope of GHG in Article 21 of the Basic Environment Act before the GHG Reduction Act passes in the Legislation Yuan.

\footnotetext{
33 Kyoto Protocol to the Framework Convention on Climate Change annex A, U.N. Doc. FCCC/CP/1997/7/Add.1 (Dec. 10, 1997), reprinted in 37 I.L.M. 22 (1998).

34 Supra note 1, art. 3.

35 Supra note 16. Article 21 states that: "Government entities at all levels shall actively adopt measures to control carbon dioxide emissions and establish related plans to mitigate the greenhouse effect," available at http://db.lawbank.com.tw/ Eng/FLAW/FLAWDAT0201.asp (last visited on May 5, 2011).
} 


\section{Other Mitigation Policies and Measures}

\section{A. The Statute for Renewable Energy Development}

The development of alternative energy is one of the national mitigation measures taken up by the Taiwanese government. To promote the usage of renewable energies and reduce domestic emissions from burning fossil fuels, the Legislation Yuan instituted the Statute for Renewable Energy Development36 in 2009.

Articles 3 and 4 of this Statute list the different types of renewable energy and the authority that will promote renewable energy-power-generating facilities. ${ }^{37}$ Article 6 of the Statute allows twenty years for the authority to promote renewable energy and requires it to establish a target for renewable energy usage every two years. Even in this case, the usage of renewable energy will still be a non-binding regulation. The authority can easily decide to change the usage target without approval from the legislative branch.

This Statute requires the state-owned Taiwan Power Company, the only power company in Taiwan integrating the electric smart grids, to purchase electricity generated by the renewable energy facilities. 38 The Department of Economy shall institute a special committee for stipulating the wholesale rate and formula for calculating power generated by renewable energy facilities. ${ }^{39}$ Companies establishing the renewable energy generating facilities to produce electricity may also file an application for subsidizing incurred expenses on incremental cost and expenses. 40

The flexible wholesale price makes the investors hesitant to facilitate the renewable energy power generators because the committee regulates purchase prices and the decision process is not transparent. Recent disputes that arose in southern Taiwan confirmed the concerns of the renewable energy investors when the Taiwan Power Company reduced the electricity purchase price for private solar power. 41 The flexible purchase price and single buyer seriously undermine an investor's interest on new energy investments. The government should consider adopting a fixed purchase price

36 The Statute for Renewable Energy Development (Aug. 7, 2009) (Taiwan), the Gazette of the Office of the President, No. 6871 , at 13 .

37 Id. arts. $3 \& 4$.

38 Id. art. 8.

$39 \quad$ Id. art. 9.

40 Id. art. 10.

41 Taipower Blasted for Falling to Pay for Private Solar Power, The China Post, Dec. 23, 2010, available at http://www.chinapost.com.tw/taiwan/national/national-news/2010/12/23/284804/Taipower-blasted.htm (last visited on May 5, 2011). 
with a specific duration to encourage the investors to purchase new renewable energy generators.

On the other hand, even if the regulations provide fixed purchase and subsidies on the renewable energy power generators, these investors cannot submit an application to the UNFCCC as part of the clean development mechanism ("CDM") project. 42 The nonKyoto Protocol membership limits Taiwan from hosting CDM projects to attract foreign investors even though Article 4 of the Convention requires that the Parties consider "the specific needs and concerns of developing countries...especially on small island countries..." 43 As an island state, Taiwan experiences the impact of climate change. It should be able to enjoy the benefits from the flexible mechanisms of industrial countries. Due to the limitations of its membership-status, Taiwan has been dealing with the adverse impacts of climate change on its own. Article 3, paragraph 1 of the UNFCCC states: "The Parties should protect the climate system for the benefit of present and future generations of humankind, on the basis of equity and in accordance with their common but differentiated responsibilities and respective capacities." 44 The Parties should provide adequate assistance to Taiwan to help it face the challenges from climate change. The limitations on Taiwan violate the 'equity' and "common but differentiated responsibilities" principle. Such limitations force Taiwan to take on more responsibilities than other developing countries even when it shares the same goal as the community. 45 Therefore, the Parties should consider all government agencies in charge of the matters covered by this Convention as an adequate participant.

\section{B. Taiwan's Voluntary GHG Reduction Program: A Draft Strategy for Assisting Domestic Emission Sources to Acquire Foreign CDM Credits to Offset GHG Emissions}

Although Taiwan is currently not subject to the Kyoto reduction commitment, the government still plans to adopt various voluntary mitigation measures and is willing to comply with the Kyoto rules. The Taiwanese government unilaterally believes that these voluntary and early mitigation efforts are necessary to receive recognition from the Parties of the UNFCCC. The private hi-tech manufacturing companies are concerned that their buyers from industrialized countries would share the emissionreduction responsibilities through international purchasing or original equipment

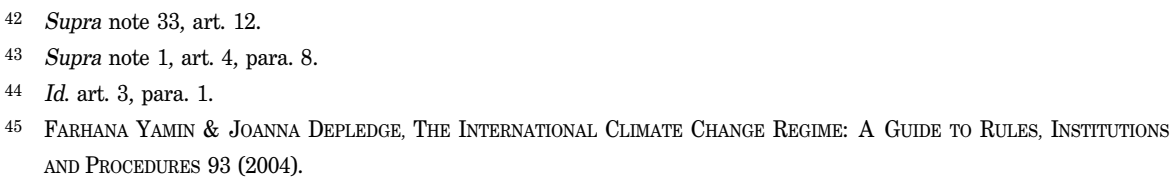

45 Farhana Yamin \& Joanna Depledge, The International Climate Change Regime: A Guide to Rules, Institutions AND PROCEDURES 93 (2004). 
manufacturing. After the GHG Reduction Act takes effect, these local emitters will face high reduction expenses to procure foreign carbon credit through the Kyoto's flexible mechanism. Their domestic emissions will be offset if the foreign carbon credit management is the most cost-effective measure for the emitters. To ensure that emitters find low-cost measures and offset project and acquire carbon credits with international credibility, 46 the emitter can participate in the Kyoto flexible mechanisms through its overseas subsidiaries just as that of countries listed in Annex I.

The Taiwanese government also plans to invite local emitters to establish a joint entity in Annex I Party countries. The Taiwan EPA and private sectors can invest in the CDM projects through this cooperation with countries listed at Annex I. These privatepublic partnership corporations will be an operational base for the Taiwanese emitters to acquire foreign carbon credits and participate in the CDM projects in developing countries. The projects include "carbon funds, emission trading and implementing CDM projects under the Kyoto Protocol." 47 The EPA will order the foreign cooperation in Annex I countries to "apply for a holding account for CDM credits management." 48 If the foreign carbon reduction project is approved and issued by the CDM Executive Board, the Taiwan EPA will allow and recognize those foreign-acquired credits to be used by the emitter to offset its emission in Taiwan.

There are two major legal concerns on this foreign CDM credit project. First, based on Decision 3 of the first Conference of the Parties serving as Meeting of Parties ("CMP.1") in 2005,49 the foreign entity owned by Taiwanese emitters and the publicprivate jointly cooperation entity in Annex I countries are not capable of applying for the holding account from CDM credit management. The CDM Executive Board is required to establish and maintain the CDM registry with four types of accounts: The holding account is within the CDM registry that is "for each Party not included in Annex I hosting a CDM project activity or requesting an account." 50 Therefore, the Decision 3/CMP.1 only allows the developing country Parties to either host a CDM project, or request to apply for the holding account from the CDM Executive Board.

Environmental Protection Administration Executive Yuan (Taiwan), Taiwan's Voluntary GHG Reduction Program: Strategies for Assisting Domestic Emission Sources to Acquire Foreign CDM Credits to Offset GHG Emissions (Draft), at 7, available at http://unfccc.epa.gov.tw/unfccc/english/_uploads/Taiwans_Voluntary_GHG_Reduction_ Program.pdf (last visited on May 5, 2011).

47 Id. at 8.

48 Id. at 9.

49 UNFCCC, Conference of the Parties serving as the Meeting of the Parties to the Kyoto Protocol, $1^{\text {st }}$ Sess., Nov. 28 Dec. 10, 2005, Montreal, Canada, Report of the Conference of the Parties serving as the Meeting of the Parties to the Kyoto Protocol, Dec. 3/ CMP.1 \& app. D, U.N. Doc. FCCC/KP/CMP/2005/8/Add.1 (Mar. 30, 2006), available at http://afoludata.jrc.ec.europa.eu/events/Kyoto_technical_workshop/08a01.pdf (last visited on May 5, 2011).

50 Id. annex D, para. 3, at 27. 
Based on the voluntary foreign CDM credit-acquiring proposal, Taiwan's EPA suggests both the private emitters and the joint corporations to establish an entity in Annex I countries for the CDM activities in which they participate. 51 These registered entities in the Annex I countries, however, are not capable of applying the holding account because they are neither the entities, nor the applicant hosting the CDM project from a developing country. In other words, the entities from Annex I countries cannot apply the holding account under the CDM registry. The suggestion to apply the holding account through an Annex I registered entity is incorrect and misstates the function of the holding account. Obviously, the registered entity in Annex I shall apply accounts from the national registry system in Annex I countries. It is quite different from the holding account that is established and maintained by the CDM Executive Board. It shows that the Taiwanese government has little understanding of the climate-related regulations and decisions. Further education for government officers and professionals are necessary. 52

Second, the foreign CDM credits are issued and reviewed by the CDM Executive Board and the Designed Nation Agency ("DNA") of the host country. These carbonreduction credits could be defined as 'legal rights,' including private property rights or commodity.53 Both the international treaties and the domestic laws of a host country create exchangeable rights of the credits among the Parties. This voluntary GHG reduction program states that the Taiwan EPA will allow the emission source "to use the credit in the foreign registry to offset domestic emissions" and apply it to the Taiwanese government. The Taiwan EPA will then issue an equal number of reduction credits. However, the UNFCCC and the Kyoto Protocol are non-binding and the credits are not enforceable within Taiwan's judicial jurisdiction. These credits are also not the legal subject for trading. These foreign reduction credits can be recognized through legislature proceedings or approved by the administrative orders. Both the Basic Environment Act and the draft GHG Reduction Act, however, do not define the legal nature of the credits at the domestic level; No rule exists that provides legal resources for credits transaction and exchange among local emitters. Before the program starts, it is necessary to define the rights of the foreign and domestic credits in the law. Otherwise, the emitters will not follow this program, recognizing that they are not protected for their efforts in reducing emission levels.

If the credits contain private property rights, permission to allow these local emitters

\footnotetext{
Supra note 46 , at 9.

52 Supra note 5, at 53.

53 David Freestone \& Charlotte Streck (ed.), Legal Aspects of Implementing the Kyoto Protocol Mechanisms: MAKING KYOTO WORK 42 (2005).
} 
to use foreign-acquired credits to offset their local emissions will lead to legal concerns on property infringement. During the transaction, the emitter needs to move his or her CERs to the cancellation account within the Annex I country's national registry system. When the CERs moves into the cancellation account, the authority contents in the reduction credit expire, becoming null and void within the climate-change regime. It would be impossible for the Taiwanese legislature to adopt law; they just recognize a credit without legally binding interest. Thus, the voluntary CDM program suggests that the emitters "apply to the National Registry of the Annex I country to transfer the credits to the cancellation account." However, this is not a good suggestion as it can nullify those foreign credits. The Taiwan EPA should conduct further research on climate-change related decisions.

The last concern is the legal source for establishing a partnership between the public and private sector among Annex I countries. Such an institutional partnership should be authorized by law, especially since acquiring foreign reduction is an alternative measure for emitters to reach the reduction commitment through cost-efficiency analysis. It is doubtful whether the government is ready to conduct such public-private partnership and assist the private emitter to engage in reduction activities.

\section{Adaptation Policies}

The EPA in Taiwan has identified fresh-water resources, agriculture and food, human health, the continental ecosystem, and both coastal and marine ecosystems as the most vulnerable sectors facing the adverse impacts of climate change.54 At this time, the government has yet to develop national-adaptation strategies. The UNDP has developed a guideline of adaptation policies for developing countries. 55 Decision 28 of the 7th session of COP provides guidelines for the preparation of the National Adaptation Program of Action ("NAPA"). 56 In accordance with the decision, the adaptation action starts by establishing a national NAPA team. This NAPA team should

Environmental Protection Administration Executive Yuan (Taiwan), The ROC's Adaptation Strategy (only available in Chinese), available at http://www.epa.gov.tw/ch/artshow.aspx?busin=12379\&art=2009011711401204\&path=12418 (last visited on May 5, 2011).

55 Bo Lim, Erika Spanger-Siegrried, Ian Burton, Elizabeth Malone \& SaleEmul HuQ, Adaptation Policy Frameworks for Climate Change: Developing Strategies, Policies and Measures 7 (2004).

56 UNFCCC, Conference of the Parties, Oct. 29 - Nov. 10, 2001, Report of the Conference on the Parties, 7th Sess., Marrakesh, Morocco, Decision 28/CP. 7 \& Annex, at 7-13, U.N. Doc. FCCC/CP/2001/13/Add. 4 (Jan. 21, 2002), available at http://unfcc.int/resource/docs/cop7/13a04.pdf (last visited on May 5, 2011). 
assemble multi-disciplinary groups to synthesize information on the adverse effects and the associated risks of climate change in case of climate variability and extreme weather events. Based on the risk priorities and selection criteria, the NAPA team should initiate a proposal for activities against the impacts of climate change. This proposal shall also be open for public review and government endorsement.

In comparing the adaptation policies of Taiwan with those in other developing countries, Taiwan did not establish the NAPA team to collect information and data to identify risks caused by climate change. Although the government identified the most vulnerable sectors within the island, it neither gives priority over the risks and vulnerabilities for developing the adaptation measures for each sector, nor completes the national adaptation policies and measures. Therefore, the Taiwanese government shall consider the guidelines of the COP decision and establish an NAPA team to uniform data and criteria for climate-information assessment. This would be the foundation for developing Taiwan's national adaptation program and action plan.

\section{Needs for Capacity Building on Local Legal System}

Article 3 of the Convention provides the principles for developing global mitigation and adaptation policies and measures, including equity, common but differentiated responsibilities, precautionary and sustainable development, etc. 57 Due to limited opportunities to participate in climate change-related meetings and negotiations, the Taiwanese government and the public could not easily follow up on the issues or concerns. These limitations hinder public awareness and discussions on global climate governing policies and measures. Moreover, the Taiwanese President is unable to both exercise his constitutional power to approve treaties, and ask the Legislation Yuan to approve it. 58

Most of the questions concerning the global environment would be executed through the administrative orders or legislative proposals by technocrats. As the global environment is fast changing, however, the international society has been developing many new principles and guidelines governing environmental issues. These new

\footnotetext{
Supra note 1, art. 3.

58 Constitution of Republic of China arts. 38 \& 63. Article 38 states that: "The President shall, in accordance with the provisions of this Constitution, exercise the powers of concluding treaties, declaring war and making peace." Article 63 states that: "The Legislative Yuan shall have the power to decide by resolution upon statutory or budgetary bills or bills concerning martial law, amnesty, declaration of war, conclusion of peace or treaties, and other important affairs of the State."
} 
principles and guidelines were not originated from Taiwan's legal initiatives because it is not entitled to participate in the international lawmaking process on climate change. For example, the COP decision requires the Parties to conduct NAPA by following the principle of precaution. If Taiwan develops its national adaptation plan by following the precautionary principle, its government would have difficulty in applying this rule to its domestic legal system because there is no such a legal concept there. Such an inconsistent situation lying between treaties concerning climate change will prevent the international community from implementing the effective global mitigation and adaptation strategies. This implies that the global society would not follow the principle of equity to allocate responsibilities to Taiwan. Fully considering Taiwan's situation, contracting Parties of the Convention should approve Taiwan's participation based on the principle of equity, common prosperity, and sustainable development.

\section{Conclusion and Suggestions}

Without a UN and UNFCCC membership, Taiwan's mitigation policies and measures do not have strong support to commit to reducing domestic GHG emissions. Thus, Taiwan has not been able to reach both domestic and global requirements for reducing GHG emission levels. The on-going GHG Reduction Act should be changed into "the GHG Inventory Investigation Act" or "Building Mitigation Capacities Act." Although such mitigation actions require the least funds and incorporate with domestic technology development, it does not fulfill the principle of cost-effectiveness and nonregret under Article 3 of the Convention.

The proposed strategy to procure foreign reduction credit through CDM shall have further studies and analysis on the related regulations. This carbon management strategy allows emitters to offset their emission by acquiring foreign reduction credits. It will also lead to concerns about fairness, especially when Taiwan has yet to establish fixed emission-reduction targets. Such actions neither reduce the local and global GHG emissions, nor meet the requirements of local and the Conventional regulations.

In order to develop domestic capacity building, further cooperation and assistance would be required from the global society. Although Taiwan has the economic capacity as well as scientific technology, it needs further assistance from its institutional and legal systems to establish the proper regulations and policies concerning the changing environment. The limitations of the Convention excluded Taiwan from sharing its experiences with the least developing countries on natural disaster recovery 
management. It has also excluded Taiwanese experts from learning through global negotiations and meetings. Taiwan may take a voluntary option for adaptation or mitigation under the climate change regime. Nevertheless, it will not be the only principles Taiwan adopts. Taiwan is taking the responsibility at its own expense and efforts. Taiwan's non-membership to the UNFCCC may be accompanied by various adverse consequences in developing local mitigation and adaptation policies and measures. Climate change is a major environmental issue of the contemporary world. It is not only a risk for all humankind, but also the best interest of the international community to take appropriate measures and actions to prevent the adverse effects. Since all human beings are responsible for GHG emissions, we should also take responsibilities for sharing the mitigating activities and expenses. Taiwan's participation in UNFCCC should be promoted by the UN under the principle of 'universal apply' on the international health regulations. 59

59 WHO, Revision of the International Health Regulations, art. 3, para. 3, repinted in 44 I.L.M. 1013 (May 23, 2005), available at http://www.who.int/csr/ihr/WHA58-en.pdf (last visited on May 5, 2011). 
